\title{
Where Do New Ideas Come From? A Heuristics of Discovery in the Cognitive Sciences ${ }^{1}$
}

\author{
Gerd Gigerenzer \\ Max Planck Institute for Human Development, Berlin, Germany
}

Scientific inquiry can be viewed as "an ocean, continuous everywhere and without a break or division," in Leibniz's words (1690/1951, p. 73). Hans Reichenbach nonetheless divided this ocean into two great seas, the context of discovery and the context of justification. Philosophers, logicians, and mathematicians claimed justification as a part of their territory and dismissed the context of discovery as none of their business, or even as "irrelevant to the logical analysis of scientific knowledge" (Popper, 1935/1959, p. 31). Their sun shines over one part of the ocean and has enlightened us on matters of justification, but the other part of the ocean still remains in a mystical darkness where imagination and intuition reigns, or so it is claimed. Popper, Braithwaite, and others ceded the dark part of the ocean to psychology and, perhaps, sociology; but few psychologists have fished in these waters. Most did not dare or care.

In this article, I will argue that discovery can be understood by heuristics (not a logic) of discovery. I will propose a heuristic of discovery that makes use of methods of justification, thereby attempting to bridge the artificial distinction between the two. Furthermore, I will attempt to demonstrate that this discovery heuristic may not only be of interest for an a posteriori understanding of theory development, but also be useful for understanding limitations of present-day theories and research programs and for the further development of alternatives and new possibilities. The discovery heuristic that I call the "tools-to-theories" heuristic (see Gigerenzer, 1991, 2000) postulates a close connection between the shining and the dark part of Leibniz's ocean: scientists' tools for justification provide the metaphors and concepts for their theories.

The power of tools to shape, or even to become, theoretical concepts is an issue largely ignored in both the history and philosophy of science. Inductivist accounts of discovery, from Bacon to Reichenbach and the Vienna School, focus on the role of data, but do not consider how the data are generated or processed. Nor do the numerous anecdotes about discoveries, such as Newton watching an apple fall in his mother's orchard while pondering the mystery of gravitation, Galton taking shelter from a rainstorm during a country outing when discovering correlation and regression toward mediocrity, and the stories about Fechner, Kekulé, Poincaré, and others, which link discovery to beds, bicycles, and bathrooms. What unites these anecdotes is the focus on the vivid but prosaic circumstances; they report the setting in which a discovery occurs, rather than analyzing the process of discovery.

1 This article is based on Gigerenzer, G. (1991). From tools to theories: A heuristics of discovery in cognitive psychology. Psychological Review, 98, 254-267; Gigerenzer, G., \& Goldstein, D. G. (1996). Mind as computer: The birth of a metaphor. Creativity Research Journal, 9, 131-144; and on chapters 1 and 2 in my book Adaptive thinking: Rationality in the real world. Oxford University Press, 2000. For permission to reprint parts of these texts, I am grateful to the American Psychological Association, to Lawrence Erlbaum Associates, and to Oxford University Press. 
The question "Is there a logic of discovery?" and Popper's (1935/1959) conjecture that there is none have misled many into assuming that the issue is whether there exists a logic of discovery or only idiosyncratic personal and accidental reasons that explain the "flash of insight" of a particular scientist (Nickles, 1980). I do not think that formal logic and individual personality are the only alternatives, nor do I believe that either of these is a central issue for understanding discovery.

The process of discovery can be shown, according to my argument, to possess more structure than thunderbolt guesses but less definite structure than a monolithic logic of discovery, of the sort Hanson (1958) searched for, or a general inductive hypothesis-generation logic (e.g., Reichenbach, 1938). The present approach lies between these two extremes; it looks for structure beyond the insight of a genius, but does not claim that the tools-to-theories heuristic is (or should be) the only account of scientific discovery. The tools-to-theories heuristic applies neither to all theories in science nor to all cognitive theories; it applies to a specific group of cognitive theories developed after the so-called cognitive revolution, in the last three decades.

Nevertheless, similar heuristics have promoted discovery in physics, physiology, and other areas. For instance, it has been argued that once the mechanical clock became the indispensable tool for astronomical research, the universe itself became understood as a kind of mechanical clock, and God as a divine watchmaker. Lenoir (1986) shows how Faraday's instruments for recording electric currents shaped the understanding of electrophysiological processes by promoting concepts such as "muscle current" and "nerve current."

Thus, this discovery heuristic boasts some generality both within cognitive psychology and within science, but this generality is not unrestricted. Since there has been little research in how tools of justification influence theory development, the tools-to-theories heuristic may be more broadly applicable than I am able to show in this article. If my view of heuristics of discovery as a heterogeneous bundle of search strategies is correct, however, this implies that generalizability is in principle bounded.

What follows has been inspired by Herbert Simon's notion of heuristics of discovery, but goes beyond his attempt to model discovery with programs such as BACON that attempt to induce scientific laws from data (e.g., Langley, Simon, Bradshaw, \& Zytkow, 1987). My focus is on the role of the tools that process and produce data, not the data themselves, in the discovery and acceptance of theories.

\section{How Methods of Justification Shape Theoretical Concepts}

The tools-to-theories heuristic is twofold:

(1) Discovery. Scientific tools, once entrenched in a scientist's daily practice, suggest new theoretical metaphors and theoretical concepts.

(2) Acceptance. Once proposed by an individual scientist (or a group), the new theoretical metaphors and concepts are more likely to be accepted by the scientific community if the members of the community are also users of the new tools.

By tools I mean both analytical and physical methods that are used to evaluate given theories. Analytical tools can be either empirical or non-empirical. Examples of analytical methods of the empirical kind are tools for data processing such as statistics; examples of the non-empirical kind are normative criteria for the evaluation of hypotheses such as logical consistency. Examples of physical tools of justification are measurement instruments such as clocks. In this article, I will focus on analytical rather than physical tools of justification, and among these, on techniques 
of statistical inference and hypothesis testing. My topic here will be theories of mind, and how social scientists discovered them after the emergence of new tools for data analysis, rather than of new data.

In this context, the tools-to-theories heuristic consists in the discovery of new theories by changing the conception of the mind through the analogy of the tool. The result can vary in depth from opening new general perspectives, albeit mainly metaphorical, to sharp discontinuity in specific cognitive theories caused by the direct transfer of scientist's tools into theories of mind.

This article will deal with two tools that have turned into cognitive theories: inferential statistics and the digital computer.

\section{Cognition as Intuitive Statistics}

I begin with a brief history. In American psychology, the study of cognitive processes was suppressed in the early 20th century by the allied forces of operationalism and behaviorism. The operationalism and the inductivism of the Vienna School, inter alia, paved the way for the institutionalization of inferential statistics in American experimental psychology between 1940 and 1955 (Gigerenzer, 1987a; Toulmin \& Leary, 1985). In experimental psychology, inferential statistics became almost synonymous with scientific method. Inferential statistics, in turn, provided a large part of the new concepts of mental processes that have fueled the so-called cognitive revolution since the 1960s. Theories of cognition were cleansed of terms such as restructuring and insight, and the new mind came to be portrayed as drawing random samples from nervous fibers, computing probabilities, calculating analyses of variance, setting decision criteria, and performing utility analyses.

After the institutionalization of inferential statistics, a broad range of cognitive processes-conscious and unconscious, elementary and complex-were reinterpreted as involving "intuitive statistics." For instance, W. P. Tanner and his coworkers assumed in their theory of signal detectability that the mind "decides" whether there is a stimulus or only noise, just as a statistician of the Neyman-Pearson school decides between two hypotheses (Tanner \& Swets, 1954). In his causal attribution theory, Harold H. Kelley (1967) postulated that the mind attributes a cause to an effect in the same way as behavioral scientists have come to do, namely, by performing an analysis of variance and testing null hypotheses. These two influential theories show the breadth of the new conception of the "mind as an intuitive statistician" (Gigerenzer, 2000; Gigerenzer \& Murray, 1987). They also exemplify cognitive theories that were suggested not by new data, but by new tools of data analysis.

In what the following, I shall give evidence for three points. First, the discovery of theories based on the conception of the mind as an intuitive statistician caused discontinuity in theory rather than being merely a new, fashionable language: it radically changed the kind of phenomena reported, the kinds of explanations looked for, and even the kinds of data that were generated. This first point illustrates the profound power of the tools-to-theories heuristic to generate quite innovative theories. Second, I will provide evidence for the "blindness" or inability of researchers to discover and accept the conception of the mind as an intuitive statistician before they became familiar with inferential statistics as part of their daily routine. The discontinuity in cognitive theory is closely linked to the preceding discontinuity in method, that is, to the institutionalization of inferential statistics in psychology. Third, I will show how the tools-to-theories heuristic can help us to see the limits and possibilities of current cognitive theories that investigate the mind as an "intuitive statistician." 


\section{Discontinuity in Cognitive Theory Development}

What has been called the "cognitive revolution" (Gardner, 1985) is more than the overthrow of behaviorism by mentalist concepts. The latter have been a continuous part of scientific psychology since its emergence in the late 19th century, even coexisting with American behaviorism during its heyday (Lovie, 1983). The cognitive revolution did more than revive the mental; it has changed our concepts of what the mental means, often dramatically. One source of this change is the tools-to-theories heuristic, with its new analogy of the mind as an intuitive statistician. To show the discontinuity within cognitive theories, I will briefly discuss two areas in which an entire statistical technique, not only a few statistical concepts, became a model of mental processes: stimulus detection and discrimination, and causal attribution.

What intensity must a $440-\mathrm{Hz}$ tone have to be perceived? How much heavier than a standard stimulus of $100 \mathrm{gms}$ must a comparison stimulus be, in order for a perceiver to notice a difference? How can the elementary cognitive processes involved in those tasks, known today as "stimulus detection" and "stimulus discrimination" be understood? Since Herbart (1816), such processes have been explained by using a threshold metaphor: detection occurs only if the effect an object has on our nervous system exceeds an absolute threshold, and discrimination between two objects occurs if the excitation from one exceeds that from the other by an amount greater than a differential threshold. E. H. Weber and G. T. Fechner's laws refer to the concept of fixed thresholds; Titchener (1896) saw in differential thresholds the long sought-after elements of mind (he counted approximately 44,000); and classic textbooks such as Brown and Thomson's (1921) and Guilford's (1954) document methods and research.

Around 1955, the psychophysics of absolute and differential thresholds was revolutionized by the new analogy between the mind and the statistician. W. P. Tanner and others proposed a "theory of signal detectability" (TSD), which assumes that the Neyman-Pearson technique of hypothesis testing describes the processes involved in detection and discrimination. Recall that in Neyman-Pearson statistics, two sampling distributions (hypotheses $\mathrm{H} 0$ and $\mathrm{Hl}$ ) and a decision criterion (which is a likelihood ratio) are defined, and then the data observed are transformed into a likelihood ratio and compared with the decision criterion. Depending on which side of the criterion the data fall, the decision to "reject $\mathrm{HO}$ and accept $\mathrm{HI}$ " or "accept $\mathrm{H} 0$ and reject $\mathrm{HI}$ " is made. In straight analogy, TSD assumes that the mind calculates two sampling distributions for "noise" and "signal plus noise" (in the detection situation) and sets a decision criterion after weighing the cost of the two possible decision errors (Type I and Type II errors in Neyman-Pearson theory, now called "false alarms" and "misses"). The sensory input is transduced into a form that allows the brain to calculate its likelihood ratio, and depending on whether this ratio is smaller or larger than the criterion, the subject says: "no, there is no signal" or "yes, there is a signal." Tanner (1965) explicitly referred to his new model of the mind as a "Neyman-Pearson detector," and in unpublished work, his flow charts included a drawing of a homunculus statistician performing the unconscious statistics in the brain (Gigerenzer \& Murray, 1987, pp. 43-53).

The new analogy between mind and statistician replaced the century-old concept of a fixed threshold by the twin notions of observer's attitudes and observer's sensitivity. Just as NeymanPearson technique distinguishes between a subjective part (e.g., selection of a criterion dependent on cost-benefit considerations) and a mathematical part, detection and discrimination became understood as involving both subjective processes, such as attitudes and cost-benefit considerations, and sensory processes. Swets, Tanner, and Birdsall (1964, p. 52) considered this link between attitudes and sensory processes to be the "main thrust" of their theory. The analogy between technique and mind made new research questions thinkable, such as "How can the mind's 
decision criterion be manipulated?" A new kind of data even emerged: two types of errors were generated in the experiments, false alarms and misses, just as the statistical theory distinguishes two types of error.

As far as I can tell, the idea of generating these two kinds of data (errors) was not common before. The discovery of TSD was not motivated by new data; rather, the new theory motivated a new kind of data. In fact, in their seminal paper, Tanner and Swets (1954, p. 401) explicitly admit that their theory "appears to be inconsistent with the large quantity of existing data on this subject," and proceed to criticize the "form of these data."

The Neyman-Pearsonian technique of hypothesis testing was subsequently transformed into a theory of a broad range of cognitive processes, ranging from recognition in memory (e.g., Murdock, 1982; Wickelgreen \& Norman, 1966) to eyewitness testimony (e.g., Birnbaum, 1983) to discrimination between random and nonrandom patterns (e.g., Lopes, 1982).

My second example concerns theories of causal reasoning. In Europe, Albert Michotte (1946/1963), Jean Piaget (1930), the Gestalt psychologists, and others had investigated how certain temporal spatial relationships between two or more visual objects, such as moving dots, produced phenomenal causality. For instance, the subjects were made to "perceive" that one dot launches, pushes, or chases another. After the institutionalization of inferential statistics, Harold H. Kelley (1967) proposed in his "attribution theory" that the long-sought laws of causal reasoning are, in fact, the tools of the behavioral scientist: R. A. Fisher's analysis of variance (ANOVA). Just as the experimenter has come to infer a causal relationship between two variables by calculating an analysis of variance and performing an F-test, the man-in-the-street infers the cause of an effect by unconsciously making the same calculations. By the time Kelley discovered the new metaphor for causal inference, about $70 \%$ of all experimental articles already used ANOVA (Edgington, 1974).

The theory was quickly accepted in social psychology; Kelley and Michaela (1980) reported more than 900 references in one decade. The vision of the Fisherian mind radically changed the understanding of causal reasoning, the problems posed to the subjects, and the explanations looked for. I list a few discontinuities that reveal the fingerprints of the tool.

(1) ANOVA needs repetitions or numbers as data in order to estimate variances and covariances. Consequently, the information presented to the subjects in studies of causal attribution consists of information about the frequency of events (e.g., McArthur, 1972), which played no role in either Michotte's or Piaget's work.

(2) Whereas Michotte's work still reflects the broad Aristotelian conception of four causes (see Gavin, 1972), and Piaget (1930) distinguished 17 kinds of causality in children's minds, the Fisherian mind concentrates on the one kind for which ANOVA is used as a tool (similar to Aristotle's "material cause").

(3) In Michotte's view, causal perception is direct and spontaneous and needs no inference, as a consequence of largely innate laws that determine the organization of the perceptual field. ANOVA, in contrast, is used in psychology as a technique for inductive inferences from data to hypotheses, and the focus in Kelley's attribution theory is consequently on the data-driven, inductive side of causal perception.

The latter point illustrates that the specific use of a tool, that is, its practical context rather than its mathematical structure, can also shape theoretical conceptions of mind. To elaborate on this point, let us assume that Harold Kelley had lived one and a half centuries earlier. In the early 19th century, significance tests (similar to those in ANOVA) were already being used by astronomers (Swijtink, 1987). However, they used their tests to reject data, so-called outliers, and not to reject hypotheses. At least provisionally, the astronomers assumed that the theory was correct and 
mistrusted the data, whereas the ANOVA mind, following the current statistical textbooks, assumes the data to be correct and mistrusts the theories. So, to our 19th-century Kelley, the mind's causal attribution would have seemed expectation-driven rather than data-driven: the statistician homunculus in the mind would have tested the data and not the hypothesis.

These two areas - detection and discrimination, and causal reasoning — may be sufficient to illustrate some of the fundamental innovations in the explanatory framework, in the research questions posed, and in the kind of data generated. The spectrum of theories that model cognition after statistical inference ranges from auditory and visual perception to recognition in memory, and from speech perception to thinking and reasoning (Gigerenzer \& Murray, 1987; Gigerenzer, 1991, 1994).

To summarize: the tools-to-theories heuristic can account for the discovery and acceptance of a group of cognitive theories in apparently unrelated subfields of psychology, all sharing the view that cognitive processes can be modeled by statistical hypothesis testing. Among these are several highly innovative and influential theories that have radically changed our understanding of what "cognitive" means.

\section{Before the Institutionalization of Inferential Statistics}

There is an important test case for the present hypothesis (a) that familiarity with the statistical tool is crucial to the discovery of corresponding theories of mind, and (b) that the institutionalization of the tool within a scientific community is crucial to the broad acceptance of those theories. That test case is the era prior to the institutionalization of inferential statistics. Theories that conceive of the mind as an intuitive statistician should have a very small likelihood of being discovered, and even less likelihood of being accepted. The two strongest tests are cases where (a) someone proposed a similar conceptual analogy, and (b) someone proposed a similar probabilistic (formal) model. The chances of theories of the first kind being accepted should be small, and the chances of a probabilistic model being interpreted as "intuitive statistics" should be similarly small. I know of only one case each, which I will analyze after first defining what I mean by the term "institutionalization of inferential statistics."

Statistical inference has been known for a long time, but not used as theories of mind. In 1710, John Arbuthnot proved the existence of God using a kind of significance test; as mentioned above, astronomers used significance tests in the 19th century; G. T. Fechner's statistical text Kollektivmasslehre (1897) included tests of hypotheses; W. S. Gosset (using the pseudonym "Student") published the t-test in 1908; and Fisher's significance-testing techniques, such as ANOVA, as well as Neyman-Pearsonian hypothesis-testing methods have been available since the 1920s (Gigerenzer et al., 1989). Bayes' theorem has been known since 1763. Nonetheless, there was little interest in these techniques in experimental psychology before 1940 (Rucci \& Tweney, 1980).

The statisticians' conquest of new territory in psychology began in the 1940s. By 1942, Maurice Kendall could comment on the statisticians' expansion: "They have already overrun every branch of science with a rapidity of conquest rivaled only by Attila, Mohammed, and the Colorado beetle" (p. 69). By the early 1950s, half of the psychology departments in leading American universities offered courses on Fisherian methods and had made inferential statistics a graduate program requirement. By 1955 , more than $80 \%$ of the experimental articles in leading journals used inferential statistics to justify conclusions from the data (Sterling, 1959), and editors of major journals made significance testing a requirement for the acceptance of articles submitted (e.g., Melton, 1962). 
I shall therefore use 1955 as a rough date for the institutionalization of the tool in curricula, textbooks, and editorials. What became institutionalized as the logic of statistical inference was a mixture of ideas from two opposing camps, those of R. A. Fisher, on the one hand, and Jerzy Neyman and Egon S. Pearson (the son of Karl Pearson) on the other.

\section{Discovery and Rejection of the Analogy}

The analogy between the mind and the statistician was first proposed before the institutionalization of inferential statistics, in the early 1940s, by Egon Brunswik at Berkeley (e.g., Brunswik 1943). As Leary (1987) has shown, Brunswiks probabilistic functionalism was based on a very unusual blending of scientific traditions, including the probabilistic world view of Hans Reichenbach and members of the Vienna School, and Karl Pearson's correlational statistics.

The important point here is that in the late 1930s Brunswik changed his techniques for measuring perceptual constancies, from calculating (non-statistical) "Brunswik ratios" to calculating Pearson correlations, such as "functional" and "ecological" validities. In the 1940s, he also began to think of the organism as "an intuitive statistician," but it took him several years to spell out the analogy in a clear and consistent way (Gigerenzer, 1987b, 2001).

The analogy is this: the perceptual system infers its environment from uncertain cues by (unconsciously) calculating correlation and regression statistics, just as the Brunswikian researcher does when (consciously) calculating the degree of adaptation of a perceptual system to a given environment. Brunswik's "intuitive statistician" was a statistician of the Karl Pearson School, like the Brunswikian researcher. Brunswik's "intuitive statistician" was not well adapted to the psychological science of the time, however, and the analogy was poorly understood and generally rejected (Leary, 1987).

Brunswik's analogy came too early to be understood and accepted by his colleagues of the experimental discipline; it came before the institutionalization of statistics as the indispensable method of scientific inference, and it came with the "wrong" statistical model, correlational statistics. Correlation was an indispensable method not in experimental psychology, but rather in its rival discipline, known as the Galton-Pearson program, or, as Lee Cronbach (1957) put it, the "Holy Roman Empire" of "correlational psychology."

The schism between the two disciplines had been repeatedly taken up in presidential addresses before the APA (Dashiell, 1939; Cronbach, 1957) and had deeply affected the values and the mutual esteem of psychologists (Thorndike, 1954). Brunswik could not succeed in persuading his colleagues from the experimental discipline to consider the statistical tool of the competing discipline as a model of how the mind works. Ernest Hilgard (1955), in his rejection of Brunswik's perspective, did not mince words: "Correlation is an instrument of the devil." (p. 228)

Brunswik, who coined the metaphor of "man as intuitive statistician," did not survive to see the success of his analogy. It was accepted only after statistical inference became institutionalized in experimental psychology, and with the new institutionalized tools rather than (Karl) Pearsonian statistics serving as models of mind. Only in the mid-1960s, however, did interest in Brunswikian models of mind emerge (e.g., Brehmer \& Joyce, 1988; Hammond \& Stewart, 2001). 


\section{Probabilistic Models Without the "Intuitive Statistician"}

My preceding point was that the statistical tool was accepted as a plausible analogy of cognitive processes only after its institutionalization in experimental psychology. My second point is that although some probabilistic models of cognitive processes were advanced before the institutionalization of inferential statistics, they were not interpreted using the metaphor of the "mind as intuitive statistician." The distinction I draw here is between probabilistic models that use the metaphor and ones that do not. The latter kind is illustrated by models that use probability distributions for perceptual judgment, assuming that variability is caused by lack of experimental control, measurement error, or other factors that can be summarized as experimenter's ignorance. Ideally, if the experimenter had complete control and knowledge (such as Laplace's superintelligence), all probabilistic terms could be eliminated from the theory. This does not hold for a probabilistic model that is based on the metaphor. Here, the probabilistic terms model the ignorance of the mind rather than that of the experimenter. That is, they model how the "homunculus statistician" in the brain comes to terms with a fundamental uncertain world. Even if the experimenter had complete knowledge, the theories would remain probabilistic, since it is the mind that is ignorant and needs statistics.

The key example is L. L. Thurstone, who in 1927 formulated a model for perceptual judgment that was formally equivalent to the present-day theory of signal detectability (TSD). But neither Thurstone nor his followers recognized the possibility of interpreting the formal structure of their model in terms of the "intuitive statistician." Like TSD, Thurstone's model had two overlapping normal distributions, which represented the internal values of two stimuli and which specified the corresponding likelihood ratios, but it never occurred to Thurstone to include the conscious activities of a statistician, such as the weighing of the costs of the two errors and the setting of a decision criterion, in his model. Thus neither Thurstone nor his followers took the-with hindsight—small step to develop the "law of comparative judgment" into TSD. When Duncan Luce (1977) reviewed Thurstone's model 50 years later, he found it hard to believe that nothing in Thurstone's writings showed the least awareness of this small, but crucial step. Thurstone's perceptual model remained a mechanical, albeit probabilistic, stimulus response theory without a homunculus statistician in the brain. The small conceptual step was never taken, and TSD entered psychology by an independent route.

In summary: there are several kinds of evidence for a close link between the institutionalization of inferential statistics in the 1950s and the subsequent broad acceptance of the metaphor of the mind as an intuitive statistician: (1) the general failure to accept, and even, to understand Brunswik's "intuitive statistician" before the institutionalization of the tool, and (2) the case of Thurstone, who proposed a probabilistic model that was formally equivalent to one important present-day theory of "intuitive statistics," but was never interpreted in this way; the analogy was not yet seen. Brunswik's case illustrates that tools may act at two levels: first, new tools may suggest new cognitive theories to a scientist. Second, the degree to which these tools are institutionalized within the scientific community to which the scientist belongs can prepare (or hinder) the acceptance of the new theory. This close link between tools for justification, on the one hand, and discovery and acceptance, on the other, reveals the artificiality of the discovery/justification distinction. Discovery does not come first, and justification afterwards. Discovery is inspired by justification. 


\section{Heuristics of Discovery May Help in Understanding Limitations and Possibilities of Current Research Programs}

The preceding analysis of discovery is of interest not only for a psychology of scientific discovery and creativity (e.g., Gardner, 1988; Gruber, 1981; Tweney, Dotherty, \& Mynatt, 1981), but also for the evaluation and further development of current cognitive theories. The general point is that institutionalized tools such as statistics are not theoretically inert. Rather, they come with a set of assumptions and interpretations that may be smuggled Trojan-horse fashion into the new cognitive theories and research programs. One example was mentioned above: the formal tools of significance testing are interpreted in psychology as tools for rejecting hypotheses, assuming that the data are correct, whereas in other fields and at other times the same tools were interpreted as tools for rejecting data (outliers), assuming that the hypotheses were correct. The latter use of statistics is practically extinct in experimental psychology (although the problem of outliers routinely emerges), and therefore also absent in theories that liken cognitive processes to significance testing. In cases like these, analysis of discovery may help to reveal "blind spots" associated with the tool and, as a consequence, new possibilities for cognitive theorizing.

There are several assumptions that became associated with the statistical tool in the course of its institutionalization in psychology, none of them being part of the mathematics or statistical theory proper. The first assumption can be called "There is only one statistics." Textbooks on statistics for psychologists (usually written by non-mathematicians) generally teach statistical inference as if only one logic of inference existed. Since the 1950s and 1960s, almost all texts teach a mishmash of R. A. Fisher's ideas tangled with those of Jerzy Neyman and Egon S. Pearson, but without acknowledgment. The fact that Fisherians and Neyman-Pearsonians could never agree on a logic of statistical inference is not mentioned in the textbooks, nor are the controversial issues that divide them. Even alternative statistical logics for scientific inference are rarely discussed (Gigerenzer, 1993, 2001). For instance, Fisher (1955) argued that concepts such as Type II error, power, the setting of a level of significance before the experiment, and its interpretation as a longrun frequency of errors in repeated experiments are concepts inappropriate for scientific inference-at best they could be applied to technology (his pejorative example was Stalin's). Neyman, for his part, declared that some of Fisher's significance tests are "worse than useless" (since their power is less than their size; see Hacking, 1965, p. 99).

I know of no textbook written by psychologists for psychologists that mentions and explains this and other controversies about the logic of inference. Instead, readers are presented with an intellectually incoherent mix of Fisherian and Neyman-Pearsonian ideas, but a mix presented as a seamless, uncontroversial whole: the logic of scientific inference (for more details see Gigerenzer et al., 1989, chaps. 3 and 6).

This assumption that "statistics is statistics is statistics"- characteristic of the practical context in which the statistical tool has been used, not of the mathematical theories-reemerges at the theoretical level in current cognitive psychology, just as the tools-to-theories heuristic would lead us to expect (Gigerenzer, 1991). For instance, research on so-called "cognitive illusions" assumes that there is one, and only one, correct answer to statistical reasoning problems. As a consequence, other answers are considered to reflect reasoning fallacies, attributed to shabby mental software. Some of the most prominent reasoning problems, however, such as the cab problem (Tversky \& Kahneman, 1980, p. 62), do not have only one answer; the answer depends on the theory of statistical inference and the assumptions applied. Birnbaum (1983), for example, shows that the "only correct answer" to the cab problem claimed by Tversky and Kahneman, based on 
Bayes' rule, is in fact only one of several reasonable answers-different ones are obtained, for instance, if one applies the Neyman-Pearson theory (Gigerenzer \& Murray, 1987, chap. 5).

A second assumption that became associated with the tool during its institutionalization is "there is only one meaning of probability." For instance, Fisher and Neyman-Pearson had different interpretations of what a level of significance means. Fisher's was an epistemic interpretation, that is, that the level of significance informs us about the confidence we can have in the particular hypothesis under test, whereas Neyman's was a strictly frequentist and behavioristic interpretation, which claimed that a level of significance tells us nothing about a particular hypothesis, but about the long-run relative frequency of wrongly rejecting the null hypothesis if it is true. Although the textbooks teach both Fisherian and Neyman-Pearsonian ideas, these alternative views of what a probability (such as level of significance) could mean are generally neglected-not to speak of the other meanings, subjective and objective, that have been proposed for the formal concept of probability (Hacking, 1965).

Many of the so-called cognitive illusions were demonstrated using a subjective interpretation of probability, specifically, asking people about the probability they assign to a single event. When researchers instead began to ask people for judgments of frequencies, these apparently stable reasoning errors-the conjunction fallacy, the overconfidence bias, for example-largely or completely disappeared (Gigerenzer, 1994, 2000a). Untutored intuition seems to be capable of making conceptual distinctions of the sort statisticians and philosophers make, such as between judgments of subjective probability and those of frequency (e.g., Cohen, 1986; Lopes, 1981; Teigen, 1983). And these results suggest that the important research questions to be investigated are "How are different meanings of 'probability' cued in every-day language?" and "How does this affect judgment?" rather than "How can we explain the alleged bias of 'overconfidence' by some general deficits in memory, cognition, or personality?"

To summarize: assumptions entrenched in the practical use of statistical tools—which are not part of the mathematics - can reemerge in research programs on cognition, resulting in severe limitations in these programs. This could be avoided by pointing out these assumptions, which, in turn, may even lead to new research questions (Gigerenzer, 2000).

I now extend my analysis from techniques of statistical inference to another tool, the computer (Gigerenzer \& Goldstein, 1996). In the first part, I argue that a conceptual divorce between intelligence and calculation around 1800, motivated by economical transformations, made mechanical computation (and ultimately the computer) conceivable. The tools-to-theories heuristic comes into play in the second part, where we show how the computer, after becoming a standard laboratory tool in this century, was proposed, and with some delay accepted, as a model of mind. Thus, we travel in a full circle from mind to computer and back.

\section{Mind as Computer}

\section{Act I: From Mind to Computer}

The president of the Astronomical Society of London, Henry Colebrooke (1825) summed up the significance of Charles Babbage's (1791-1871) work: "Mr. Babbage's invention puts an engine in place of the computer." This seems a strange statement about the man who is now praised for having invented the computer. But at Babbage's time, the computer was a human being, in this case someone who was hired for exhaustive calculations of astronomical and navigational tables. 
How did Babbage ever arrive at the idea of putting a mechanical computer in place of a human one? A divorce between intelligence and calculation, as Daston (1994) has argued, made it possible for Babbage to conceive this idea.

In the Enlightenment, calculation was not considered a rote, mechanical thought process. In contrast, philosophers of the time held that intelligence and even moral sentiment were, in their essence, forms of calculation (Daston, 1988, 1994). Calculation was the opposite of the habitual and the mechanical, remote from the realm of menial labor. For Condillac, d'Alembert, Condorcet, and other Enlightenment philosophers, the healthy mind worked by constantly taking apart ideas and sensations into their minimal elements, then, comparing and rearranging these elements into novel combinations and permutations. Thought was a combinatorial calculus, and great thinkers were proficient calculators. In the eulogies of great mathematicians, for instance, prodigious mental reckoning was a favorite topic_-Gauss' brilliant arithmetic was perhaps the last of these stock legends. Calculation was the essence of moral sentiment, as well. Even self-interest and greed, as opposed to dangerous passions, by their nature of being calculations, were at least predictable and thereby thought to reinforce the orderliness of society (Daston, 1994).

\section{The Computer as a Factory of Workers}

By the turn of the 19th century, calculation was shifting from the company of hommes éclairés and savants to that of the unskilled work force. Extraordinary mental arithmetic became associated with the idiot savant and the sideshow attraction. Calculation grew to be seen as dull, repetitive work, best performed by patient minds that lacked imagination. Women ultimately staffed the "bureaux de calculs" in major astronomical and statistical projects (despite being earlier accused of vivid imaginations and mental restlessness, see Daston, 1992). Talent and genius ceased to be virtuoso combinatorics and permutations, and turned into romantic, unanalyzable creations. Thereby, the stage became set for the neo-romanticism in 20th century philosophy of science that declared creativity as mystical, and the context of discovery as "irrelevant to the logical analysis of scientific knowledge" (Popper, 1935/1959, p. 31).

Daston (1994) and Schaffer (1994) argue that one force in this transformation was the introduction of large-scale division of labor in manufacturing, as evidenced in the automatic system of the English machine-tool industry and in the French government's large-scale manufacturing of logarithmic and trigonometric tables for the new decimal system in the 1790s. During the French revolution, the engineer Gaspard Riche de Prony organized the French government's titanic project for the calculation of 10,000 sine values to the unprecedented precision of 25 decimal places and some 200,000 logarithms to 14 or 15 decimal places. Inspired by Adam Smith's praise of the division of labor, Prony organized the project in a hierarchy of tasks. At the top were a handful of excellent mathematicians, including Adrien Legendre and Lazare Carnot, who devised the formulae; in the middle were seven or eight persons trained in analysis; and at the bottom were seventy or eighty unskilled persons knowing only the rudiments of arithmetic, who performed millions of additions and subtractions. These "manufacturing" methods, as Prony called them, pushed calculation away from intelligence and towards work. The terms "work" and "mechanical" were linked both in England and in France until the middle of the 19th century (Daston, 1994). Work concerned the body but not the mind; in large-scale manufacturing, each worker did only one task throughout his entire life.

Once it was shown that elaborate calculation could be carried out by an assemblage of unskilled workers, each knowing very little about the large computation, it became possible for Babbage to conceive of replacing these workers with machinery. Babbage's view of the computer 
bore a great resemblance to a factory of unskilled human workers. When Babbage talked about the parts of his Analytical Engine, the arithmetic computation and the storage of numbers, he called these the "mill" and the "store," respectively (Babbage 1812/1994, p. 23). The metaphor came from the textile industry. In the textile industry, yarns were brought from the store to the mill where they were woven into fabric, which was then sent back to the store. In the Analytical Engine, numbers were brought from the store to the arithmetic mill for processing, and the results were returned to the store. Commenting on this resemblance, Lady Lovelace stated, "we may say most aptly that the Analytical Engine weaves algebraic patterns just as the Jaquard loom weaves flowers and leaves" (Babbage 1812/1994, p. 27). ${ }^{2}$ In his chapter on the "division of mental labor," Babbage explicitly refers to the French government's program for the computation of new decimal tables as the inspiration and foundation of a general science of machine intelligence.

To summarize the argument: during the Enlightenment, calculation was the distinctive activity of the scientist and the genius, and the very essence of the mental life. New ideas and insights were assumed to be the product of the novel combinations and permutations of ideas and sensations. In the first decades of the 19th century, numerical calculation was separated from the rest of intelligence and demoted to one of the lowest operations of the human mind. Once calculation became the repetitive task of an army of unskilled workers, Babbage could envision mechanical computers replacing human computers. Pools of human computers and Babbage's mechanical computer manufactured numbers in the same way as the factories of the day manufactured their goods. ${ }^{3}$

\section{The Computer as a Brain}

Babbage once reported a dream: that all tables of logarithms could be calculated by a machine. However, this dream did not turn into a reality during his lifetime. He never could complete any of the three machines he had started to build. Modern computers, such as the ENIAC and the EDVAC at the University of Pennsylvania, came about during and after the Second World War. Did the fathers of computer science see the mind as a computer? We (Gigerenzer \& Goldstein, 1996) argued that the contemporary analogy stating that the mind is a computer was not yet established before the "cognitive revolution" of the 1960s. As far as we can see, there were two groups willing to draw a parallel between the human and the computer, but neither used the computer as a theory of mind. One group, which tentatively compared the nervous system to the computer, is represented by the Hungarian mathematician John von Neumann (1903-1957). The other group, which investigated the idea that machines might be capable of thought, is represented by the English mathematician and logician Alan Turing (1912-1954).

Von Neumann, known as the father of the modern computer, wrote about the possibility of an analogy between the computer and the human nervous system. It seems that his reading of a paper by Warren McCulloch and Walter Pitts called "A logical calculus of the ideas immanent in nervous activity" triggered his interest in information processing in the human brain soon after its publication in 1943 (Aspray, 1990). The paper begins with the statement that because of the all-or-none character of the nervous system, neural events can be represented by means

2 The Jaquard loom was a general-purpose device which was loaded with a set of punched cards and could weave infinite varieties of patterns. Factories in England were equipped with hundreds of these machines, and Babbage was one of the "factory tourists" of the 1830 s and 1840 s.

3 Calculation became dissociated from and opposed to not only the human intellect, but also moral impulse. Madame de Staell, for instance, used the term "calcul" only in connection with the "egoism and vanity" of those opportunists who exploited the French Revolution for their own advantage and selfishness (Daston, 1994). 
of propositional logic. The McCulloch-Pitts model did not deal with the structure of neurons, which were treated as "black boxes." The model was largely concerned with the mathematical rules governing the input and output of signals. In the 1945 EDVAC (the "Electronic Discrete Variable Computer" at the University of Pennsylvania) report, von Neumann described the computer as being built from McCulloch and Pitt's idealized neurons rather than from vacuum tubes, electromechanical relays, or mechanical switches. To understand the computer in terms of the human nervous system appeared strange to many, including the chief engineers of the ENIAC project, Eckert and Mauchly (Aspray, 1990, p. 173). However, von Neumann hoped that his theory of natural and artificial automata would both improve understanding of the design of computers and the human nervous system. His last work, for the Silliman Lectures, which owing to illness he could neither finish nor deliver, was largely concerned with pointing out similarities between the nervous system and computer, the neuron and the vacuum tube-but adding cautionary notes on their differences (von Neumann, 1958).

What was the reception of von Neumann's tentative analogy between the nervous system and the computer? His intellectual biographer, William Aspray (1990, p. 181) concludes that psychologists and physiologists were less than enthusiastic about the McCulloch-Pitts model; Seymor Papert spoke of "a hostile or indifferent world" (McCulloch, 1965, p. xvii) and McCulloch himself admitted the initial lack of interest in their work (p. 9).

\section{The Computer as a Mind}

Von Neumann and others searched for a parallel between the machine and the human on the level of hardware. Alan Turing (1950), in contrast, thought the observation that both the modern digital computer and the human nervous system are electrical was based on a "very superficial similarity" (p. 439). He pointed out that the first digital computer, Babbage's Analytical Engine, was purely mechanical (as opposed to electrical), and that the important similarities to the mind are in function rather than in hardware. Turing discussed the question of whether machines can think, rather than the question of whether the mind is like a computer. Thus, he was looking in the direction opposite to that of psychologists after the cognitive revolution and, consequently, he did not propose any theories of mind. For example, the famous Turing Test is about whether a machine can imitate a human mind, but not vice versa. Turing argued that it would be impossible for a human to imitate a computer, as evidenced by human's inability to perform complex numerical calculations quickly. Turing also discussed the question of whether a computer could be said to have a free will, a property of humans. Many years later, cognitive psychologists, under the assumptions that the mind is a computer and that computers lack free will, instead pondered the question of whether humans could be said to have one. A similar story to this is that Turing (1969), in a paper written in 1947 but published only years after his death, contemplated teaching machines to be intelligent using the same principles used to teach children. The analogy of the computer as a mind was reversed again after the cognitive revolution, as McCorduck (1979) points out, when from Massachusetts Institute of Technology (MIT) psychologists tried to teach children with the very methods that had worked for computers.

Turing (1969) anticipated much of the new conceptual language and even the very problems Allen Newell and Herbert Simon were to attempt, as we will see in the second part of this paper. With amazing prophecy, Turing suggested that nearly all intellectual issues can be translated into the form "find a number $n$ such that ...," that is, that "search" is the key concept for problem solving, and that Whitehead and Russell's (1935) Principia Mathematica might be a good start for demonstrating the power of the machine (McCorduck, 1979, p. 57). 
Not only did Turing's life end early and under tragic circumstances, but his work had practically no influence on artificial intelligence in Britain until the mid-1960s (McCorduck, 1979, p. 68). Neither von Neumann nor his friends were persuaded to look beyond similarities between cells and diodes to functional similarities between humans and computers.

To summarize: two groups compared humans and computers before the cognitive revolution. One of these groups, represented by von Neumann, spoke tentatively about the computer as a brain, but warned about taking the analogy too far. The other group, represented by Turing, asked whether the computer has features of the human mind but not vice versa, that is, did not attempt to design theories of mind through the analogy of the tool.

Before the second half of the century, the mind was not yet a computer. However, a new incarnation of the Enlightenment view of intelligence as a combinatorial calculus was on the horizon.

\section{Act II: From Computer to Mind}

In this section, we see how a tools-to-theories explanation accounts for the new conception of the mind as a computer, focusing on the discovery and acceptance of Herbert Simon and Allen Newell's brand of information-processing psychology. We will try to reconstruct the discovery of Newell and Simon's (1972) information-processing model of mind and its (delayed) acceptance by the psychological community in terms of the tools-to-theories heuristic.

\section{Discovery}

Babbage's mechanical computer was preceded by human computers. Similarly, Newell and Simon's first computer program, the Logic Theorist, was also preceded by a human computer. Before the Logic Theorist was up and running, Newell and Simon reconstructed their computer program out of human components (namely, Simon's wife, children and several graduate students), to see if it would work. Newell wrote up the subroutines of the Logic Theorist (LT) program on index cards:

To each member of the group, we gave one of the cards, so that each person became, in effect, a component of the LT computer program - a subroutine - that performed some special function, or a component of its memory. It was the task of each participant to execute his or her subroutine, or to provide the contents of his or her memory, whenever called by the routine at the next level above that was then in control.

So we were able to simulate the behavior of the LT with a computer consisting of human components ... The actors were no more responsible than the slave boy in Plato's Meno, but they were successful in proving the theorems given them. (Simon, 1991, p. 207)

The parallels to Prony's bureaux de calculs and the large-scale manufacturing of the new factories of the early 19th century are striking. At essence is a division of labor, where the work is carried out by a hierarchy of humans — each requiring little skill, and repeating the same routine again and again. Complex processes are achieved by an army of workers who never see but a little piece of the larger picture. ${ }^{4}$

4 The Manhattan Project at Los Alamos, where the atomic bomb was constructed, housed another human computer. Although the project could draw on the best technology available, in the early 1940s mechanical calculators (such as the typewriter-sized Marchant calculator) could do nothing but addition, subtraction, multiplication, and, with some difficulty, division. Richard Feynman and Nicholas Metropolis arranged a pool of people (mostly scientists' wives who were getting paid three-eighths salary), each of whom repetitively performed a small calculation (such as cubing a number) and passed the result on to another person, who incorporated it into yet another computation (Gleick, 1992). 
However, between Prony's human computer and Simon's human computer, there is an important difference. Prony's human computer and Babbage's mechanical computer (which was modeled upon it) performed numerical calculations. Simon's human computer did not. Simon's humans matched symbols, applied rules to symbols, and searched through lists of symbols. In short, they performed what is now generally known as symbol manipulation.

The reader will recall from the first part of this paper that the divorce between intelligence and numerical calculation made it possible for Babbage to replace the human computer by a mechanical one. In the 21 st century, intelligence and calculation are still divorced. Given this divorce and the early conception of the computer as a fancy number cruncher, it is not surprising that the computer never suggested itself as a theory of mind. We argue that an important precondition for the view of mind as a computer is the realization that computers are symbol manipulation devices, in addition to being numerical calculators. Newell and Simon were among the first to realize this. In the interviews with Pamela McCorduck (1979, p. 129), Allen Newell recalls, "I've never used a computer to do any numerical processing in my life." Newell's first use of the computer at RAND corporation-a prehistoric card-programmed calculator hooked up to a line printer-was calculating and printing out symbols representing airplanes for each sweep of a radar antenna.

The symbol-manipulating nature of the computer was important to Simon because it corresponded to some of his earlier views on the nature of intelligence:

The metaphor I'd been using, of a mind as something that took some premises and ground them up and processed them into conclusions, began to transform itself into a notion that a mind was something which took some program inputs and data and had some processes which operated on the data and produced output. (McCorduck, 1979, p. 127)

It is interesting to note that twenty years after seeing the computer as a symbol manipulating device, Newell and Simon came forth with the explicit hypothesis that a physical symbol system is necessary and sufficient for intelligence.

The Logic Theorist generated proofs for theorems in symbolic logic, specifically, the first twenty-five or so theorems in Whitehead and Russell's (1935) Principia Mathematica. It even managed to find a proof more elegant than the corresponding one in the Principia.

In the summer of 1958, psychology was given a double-dose of the new school of information-processing psychology. One was the publication of the Psychological Review article "Elements of a Theory of Human Problem Solving" (Newell, Shaw \& Simon, 1958). The other was the Research Training Institute on the Simulation of Cognitive Processes at the RAND institute, which we will discuss later.

The Psychological Review paper is an interesting document of the transition between the view that the Logic Theorist is a tool for proving theorems in logic (the artificial intelligence view), and an emerging view that the Logic Theorist is a model of human reasoning (the information processing view). In fact, the authors go back and forth between both views, expounding on the one hand that "the program of LT [Logic Theorist] was not fashioned directly as a theory of human behavior; it was constructed in order to get a program that would prove theorems in logic" (p. 154), but on the other hand that the Logic Theorist "provides an explanation for the processes used by humans to solve problems in symbolic logic" (p. 163). The evidence provided for projecting the machine into the mind is mainly rhetorical. For instance, the authors spend several pages arguing for the resemblance between the methods of the Logic Theorist and concepts such as "set," "insight," and "hierarchy" described in the earlier psychological literature on human problem solving. 
In all fairness, despite the authors' claim, the resemblance to these earlier concepts as they were used in the work of Karl Duncker, Wolfgang Köhler and others is slight. New discoveries, by definition, clash with what has come before, but it is often a useful strategy to hide the amount of novelty and claim historical continuity. When Tanner and Swets, four years earlier (also in the Psychological Review) proposed that another scientific tool, Neyman-Pearsonian techniques of hypothesis testing, would model the cognitive processes of stimulus detection and discrimination, their signal detection model also clashed with earlier notions, such as the notion of a sensory threshold. Tanner and Swets (1954, p. 401), however, chose not to conceal this schism between the old and the new theories, explicitly stating that their new theory "appears to be inconsistent with the large quantity of existing data on this subject." As evidenced in this paper, there is a different historical continuity in which Simon and Newel's ideas stand: the earlier Enlightenment view of intelligence as a combinatorial calculus.

\section{Conceptual Change}

Newell et al. (1958) tried to emphasize the historical continuity of what was to become their new information-processing model of problem solving, as did Miller, Galanter and Pribram in their Plans and the Structure of Behavior (1960) when they linked their version of Newell and Simon's theory to many great names such as William James, Frederic Bartlett, and Edward Tolman. We believe that these early claims for historical continuity served as protection: George Miller, who was accused by Newell and Simon as having stolen their ideas and gotten them all wrong, said "I had to put the scholarship into the book, so they would no longer claim that those were their ideas. As far as I was concerned they were old familiar ideas" (Baars, 1986, p. 213). In contrast to this rhetoric, we will here emphasize the discontinuity introduced by the transformation of the new tool into a theory of mind.

\section{The New Mind}

What was later called the "new mental chemistry" pictured the mind as a computer program:

The atoms of this mental chemistry are symbols, which are combinable into larger and more complex associational structures called lists and list structures. The fundamental "reactions" of the mental chemistry employ elementary information processes that operate upon symbols and symbol structures: copying symbols, storing symbols, retrieving symbols, inputting and outputting symbols, and comparing symbols. (Simon, 1979 , p. 63)

This atomic view is certainly a major conceptual change in the views on problem solving compared to the theories of Köhler, Wertheimer, and Duncker. However, it bears much resemblance to the combinatorial view of intelligence of the Enlightenment philosophers. ${ }^{5}$

The different physical levels of a computer lead to Newel's cognitive hierarchy, which separates the knowledge-level, symbol-level, and register-transfer levels of cognition. As Arbib (1993) points out, the seriality of 1971-style computers is actually embedded in Newell's cognitive theory.

5 In fact, the new view was directly inspired by the 19th-century mathematician George Boole, who, in the very spirit of the Enlightenment mathematicians such as the Bernoullis and Laplace, set out to derive the laws of logic, algebra, and probability from what he believed to be the laws of human thought (Boole 1854/1958). Boole's algebra culminated in Whitehead and Russell's (1935) Principia Mathematica, describing the relationship between mathematics and logic, and in Claude E. Shannon's seminal work (his master's thesis at MIT in 1937), which used Boolean algebra to describe the behavior of relay and switching circuits (McCorduck, 1979, p. 41). 
One of the major concepts in computer programming that made its way into the new models of the mind is the decomposition of complexity into simpler units, such as the decomposition of a program into a hierarchy of simpler subroutines, or into a set of production rules. On this analogy, the most complex processes in psychology, such as scientific discovery, can be explained through simple subprocesses. Thus, the possibility of the logic of scientific discovery, the existence of which Karl Popper so vehemently disclaimed, has returned in the analogy between computer and mind (Langley et al., 1987).

The first general statement of Newell and Simon's new vision of mind appeared in their 1972 book Human Problem Solving. In this book, the authors argue for the idea that higher-level cognition proceeds much like the behavior of a production system, a formalism from computer science (and before that, symbolic logic) which had never been used in psychological modeling before. They speak of the influence of programming concepts on their models:

Throughout the book we have made use of a wide range of organizational techniques known to the programming world: explicit flow control, subroutines, recursion, iteration statements, local naming, production systems, interpreters, and so on. ... We confess to a strong premonition that the actual organization of human programs closely resembles the production system organization. (Newell \& Simon, 1972, p. 803)

We will not attempt to probe the depths of how Newell and Simon's ideas of information processing changed theories of mind; the commonplace usage of computer terminology in the cognitive psychological literature since 1972 is a reflection of this. How natural it seems for present-day psychologists to speak of cognition in terms of encoding, storage, retrieval, executive processes, algorithms, and computational cost.

\section{New Experiments, New Data}

The tools-to-theories heuristic implies that new theories need not be a consequence of new experiments and new data. Furthermore, new tools can transform the kinds of experiments performed and data collected. I have described this consequence of the tools-to-theories heuristic when statistical tools turned into theories of mind.

A similar story is to be told with the conceptual change brought about by Newell and Simon-it mandated a new type of experiment, which in turn involved new kinds of subjects, data, and justification. In academic psychology of the day, the standard experimental design, modeled after the statistical methods of Ronald A. Fisher, involved many subjects and randomized treatment groups. The 1958 Psychological Review paper uses the same terminology of "design of the experiment" and "subject," but radically changes their meanings. There are no longer groups of human or animal subjects. There is only one subject: an inanimate being named the Logic Theorist. There is no longer an experiment in which data are generated by either observation or measurement. Experiment takes on the meaning of simulation.

In this new kind of experiment, the data are of an unforeseen type: computer printouts of the program's intermediate results. These new data, in turn, require new methods of hypothesis testing. How did Newell and Simon determine if their program was doing what minds do? There were two methods: for Newell and Simon, simulation was a form of justification itself, that is, a theory that is coded as a working computer program shows that the processes it describes are, at the very least, sufficient to perform the task, or, in the more succinct words of Simon, "A running program is the moment of truth" (1992, p. 155). Furthermore, a stronger test of the model was made by comparing the computer's output to the think-aloud protocols of human subjects. 
Although this was all a methodological revolution in the experimental practice of the time, some important parallels exist between the new information-processing approach and the turnof-the-century German approach to studying mental processes. These parallels concern the analysis of individual subjects (rather than group means), the use of think-aloud procedures, and the status of the subject. In early German psychology, as well in American psychology of the time (until around the 1930s), the unit of analysis was the individual person, and not the average of a group (Danziger, 1990). The two most prominent kinds of data in early German psychology were reaction times and introspective reports. Introspective reports have been frowned upon ever since the inception of American behaviorism, but think-aloud protocols, their grandchildren, are back (as are reaction times).

Finally, in the tradition of the Leipzig (Wundt) and Würzburg (Külpe) schools, the subject was more prestigious and important than the experimenter. Under the assumption that the thought process is introspectively penetrable, the subject, not the experimenter, was assumed to provide the theoretical description of the thought process. In fact, the main experimental contribution of Külpe, the founder of the Würzburg school, was to serve as a subject; and it was often the subject who published the paper. In the true spirit of these schools, Newell and Simon named their subject, the Logic Theorist, as a co-author of a paper submitted to the Journal of Symbolic Logic. Regrettably, the paper was rejected (as it contained no new results from modern logic's point of view), and the Logic Theorist never tried to publish again.

\section{Acceptance}

The second dose of information processing (after the Psychological Review paper) administered to psychology was the Research Training Institute on the Simulation of Cognitive Processes at the RAND institute, organized by Newell and Simon. The institute held lectures and seminars, taught EPL-IV programming, and demonstrated the Logic Theorist, the General Problem Solver, and the EPAM model of memory on the RAND computer. In attendance were some individuals who would eventually develop computer simulation methods of their own, including George Miller, Robert Abelson, Bert Green, and Roger Shepard.

An early, but deceptive harbinger of acceptance for the new information processing-theory was the publication, directly after the summer institute of Plans and the Structure of Behavior (Miller, Galanter, \& Pribram, 1960), written mostly by George Miller. Despite the 1959 dispute with Newell and Simon (mentioned earlier) over the ownership and validity of the ideas within it, this book drew a good deal of attention from all areas of psychology.

It would seem the table was set for the new information processing psychology; however, it did not take hold. Simon complained of the psychological community who took only a "cautious interest" in their ideas. The "acceptance" part of the tools-to-theories thesis can explain this: computers were not yet entrenched in the daily routine of psychologists, as we will show.

\section{No Familiar Tools, No Acceptance}

We take two institutions as case studies to demonstrate the part of the tools-to-theories hypothesis that concerns acceptance: the Center for Cognitive Studies at Harvard, and Carnegie Mellon University. The former never came to fully embrace the new information-processing psychology. The latter did, but after a considerable delay. Tools-to-theories might explain both phenomena.

George Miller, the co-founder of the Center at Harvard, was certainly a proponent of the new information-processing psychology. As we mentioned, his book Plans and the Structure of 
Behavior was so near to Newell and Simon's ideas that it was at first considered a form of theft, although the version of the book that did see the presses is filled with citations recognizing Newell, Shaw, and Simon. Given Miller's enthusiasm, one might expect the Center, partially under Miller's leadership, to blossom into information-processing research. It never did. Looking at the Harvard University Center for Cognitive Studies Annual Reports from 1963-1969, we found only a few symposia or papers dealing with computer simulation.

Although the Center had a PDP-4C computer, and the reports anticipated the possibility of using it for cognitive simulation, as late as 1969 it never happened. The reports mention that the computer served to run experiments, to demonstrate the feasibility of computer research, and to draw visitors to the laboratory. However, difficulties involved with using the tool were considerable. The PDP saw 83 hours of use on an average week in 1965-1966, but 56 of these were spent on debugging and maintenance. In the annual reports are several remarks of the type "It is difficult to program computers ... Getting a program to work may take months." They even produced a 1966 technical report called "Programmanship, or how to be one-up on a computer without actually ripping out its wires.”

What might have kept the Harvard computer from becoming a metaphor of the mind was that the researchers could not integrate this tool into their everyday laboratory routine. The tool instead turned out to be a steady source of frustration. As tools-to-theories suggests, this lack of entrenchment into everyday practice accounted for the lack of acceptance of the new information-processing psychology. Simon (1979) has taken notice of this:

Perhaps the most important factors that impeded the diffusion of the new ideas, however, were the unfamiliarity of psychologists with computers and the unavailability on most campuses of machines and associated software (list processing programming languages) that were well adapted to cognitive simulation. The 1958 RAND Summer Workshop, mentioned earlier, and similar workshops held in 1962 and 1963, did a good deal to solve the first problem for the 50 or 60 psychologists who participated in them; but workshop members often returned to their home campuses to find their local computing facilities ill-adapted to their needs. (Simon, 1979, p. 356)

At Carnegie Mellon University, Newell, Simon, a new enthusiastic department head, and a very large National Institute of Mental Health (NIMH) grant were pushing "the new IP [information processing] religion" (Simon, 1994). Even this concerted effort failed to proselytize the majority of researchers within their own department. This again indicates that entrenchment of the new tool into everyday practice was an important precondition for the spread of the metaphor of the mind as a computer.

\section{Acceptance of Theory Follows Familiarity With Tool}

In the late 1950s, at Carnegie Mellon, the first doctoral theses involving computer simulation of cognitive processes were being written (Simon, personal communication). However, this was not representative of the national state of affairs. In the mid-1960s, a small number of psychological laboratories, including at Carnegie Mellon, Harvard, Michigan, Indiana, MIT, and Stanford were built around computers (Aaronson, Grupsmith \& Aaronson, 1976, p. 130). As indicated by the funding history of NIMH grants for cognitive research, the amount of computer-based research tripled over the next decade: in 1967, only $15 \%$ of the grants being funded had budget items related to computers (e.g., programmer salaries, hardware, supplies). By 1975, this figure had increased to $46 \%$. The late 1960 s saw a turn towards mainframe computers, which lasted until the late 1970s when the microcomputer began its invasion of the laboratory. In the 1978 Behavioral Research Methods and Instrumentation conference, microcomputers were the issue of the day (Castellan, 1981, p. 93). By 1984, the journal Behavioral Research Methods and Instru- 
mentation appended the word "Computers" to its title to reflect the broad interest in the new tool. By 1980, the cost of computers had dropped an order of magnitude from their cost in 1970 (Castellan, 1981, 1991). During the last two decades, computers have become the indispensable research tool of the psychologist.

Once the tool became entrenched into everyday laboratory routine, a broad acceptance of the view of the mind as a computer followed. In the early 1970s, information-processing psychology finally caught on at Carnegie Mellon University. In the 1973 edition of the Carnegie Symposium on Cognition, every CMU-authored article mentions some sort of computer simulation. For the rest of the psychological community, who were not as familiar with the tool, the date of broad acceptance was years later. In 1979, Simon estimated that from about 1973 to 1979, the number of active research scientists working in the information-processing vein had "probably doubled or tripled" (Simon, 1979).

This does not mean that the associated methodology became accepted as well. It clashed too strongly with the methodological ritual that was institutionalized during the 1940s and 1950s in experimental psychology. We use the term "ritual" here for the mechanical practice of a curious mishmash between Fisher's and Neyman-Pearson's statistical techniques that was taught to psychologists as the sine qua non of scientific method (Gigerenzer, 1993, 2000). Most psychologists assumed, as the textbooks had told them, that there was only one way to do good science. But their own heroes-Fechner, Wundt, Pavlov, Köhler, Bartlett, Piaget, Skinner, Luce, to name a few-had never used this "ritual"; some had used experimental practices that resembled the newly proposed methods used to study the mind as computer.

\section{Pragmatics}

Some of my experimental colleagues have objected to my analysis of how statistical tools turned into theories of mind. They argue that tools are irrelevant in discovery, and that my tool-totheories examples are merely illustrations of psychologists being quick to realize that the mathematical structure of a tool (such as analysis of variance, or the digital computer) is precisely that of the mind. It is not easy to convince someone who believes (in good Neoplatonic fashion) that today's theory of mind exactly fits the nature of the mind, that such a splendid theory might mirror something other than pure and simple reality. If it were true that tools have no role in discovery, and that the new theories just happen to mirror the mathematical structure of the tool, then the pragmatics of a tool's use (which is independent of the mathematical structure) would find no place in the new theories. However, the case of statistical tools in the first half of this article provides evidence that not only the new tool, but also its pragmatic uses are projected into the mind. The tools-to-theories heuristic cannot be used to defend a spurious Neoplatonism.

The same process of projecting the pragmatic aspects of a tool's use onto a theory can be shown for the view of the mind as a computer. One example is Levelt's model of speaking (Levelt, 1989). The basic unit in Levelt's model, which he calls the "processing component," corresponds to the computer programmer's concept of a subroutine. Gigerenzer and Goldstein (1996) argued that Levelt's model not only borrowed the subroutine as a tool, but also borrowed the pragmatics of how subroutines are constructed.

A subroutine (or "subprocess") is a group of computer instructions, usually serving a specific function, that are separated from the main routine of a computer program. It is common for subroutines to perform often-needed functions, such as extracting a cube root or rounding a number. There is a major pragmatic issue involved in writing subroutines that centers around what is called the principle of isolation (Simon, 1986). The issue is whether subroutines should 
be black boxes or not. According to the principle of isolation, the internal workings of the subroutine should remain a mystery to the main program, and the external program should remain a mystery to the subroutine. Subroutines built without respect to the principle of isolation are "clear boxes" that can be penetrated from the outside and escaped from the inside. To the computer, of course, it makes no difference whether the subroutines are isolated or not. Subroutines that are not isolated work just as well as those that are. The only difference is a psychological one. Subroutines that violate the principle of isolation are harder to read, write and debug, from a person's point of view. For this reason, introductory texts on computer programming stress the principle of isolation as the essence of good programming style.

The principle of isolation - a pragmatic feature of using subroutines- has a central place in Levelt's model, where the processing components are "black boxes" and constitute what Levelt considers to be a definition of Fodor's notion of "informational encapsulation" (Levelt, 1989, p. 15). In this way, Levelt's psychological model embodies a maxim of good computer-programming methodology: the principle of isolation. That this pragmatic feature of the tool shaped a theory of speaking is not an evaluation of the quality of the theory. Our point concerns origins, not validity. However, in this case, this pragmatic feature of the subroutine has not always served the model well: Kita (1993) and Levinson (1992) have attacked Levelt's model at its Achilles' heel-its insistence on isolation.

To summarize: I have drawn a full circle from theories of mind to computers and back to theories of mind. The argument was that economic changes-the large-scale division of labor in manufacturing and in the "bureaux de calculs"-corresponded with the breakdown of the Enlightenment conception of the mind, in which calculation was the distinctive essence of intelligence. Once calculation was separated from the rest of intelligence and relegated to the status of a dull and repetitive task, Babbage could envision replacing human computers by mechanical ones. Both human and mechanical computers manufactured numbers as the factories of the day manufactured goods. In the 20th century, the technology became available to make Babbage's dream a reality. Computers became indispensable scientific tools for everything from number crunching to simulation. Our focus was on the work by Herbert Simon and Allen Newell and their colleagues, who proposed the tool as a theory of mind. Their proposal reunited mere calculation with what was now called "symbol processing," returning to the Enlightenment conception of mind. After computers found a place in nearly every psychological laboratory, broad acceptance of the metaphor of the mind as computer followed. ${ }^{6}$ Now that the metaphor is in place, many find it hard to see how the mind could be anything else: to quote Philip Johnson-Laird (1983, p. 10), "The computer is the last metaphor; it need never be supplanted."

\section{Discovery Reconsidered}

New technologies have been a steady source of metaphors of mind: "In my childhood we were always assured that the brain was a telephone switchboard. ('What else could it be?')," recalls John Searle (1984, p. 44). The tools-to-theories heuristic is more specific than general technology metaphors. Scientists' tools for justification, not just any tools, are used to understand the

6 Our reconstruction of the path "from mind to computer and back" also provides an explanation for one widespread type of resistance against the computer metaphor of mind. The post-Enlightenment divorce between intelligence and calculation still holds to this day, and for those who still associate the computer with mere calculation (as opposed to symbol processing) the mind as a computer is a contradiction in itself. 
mind. Holograms are not social scientists' tools, but computers are, and part of their differential acceptance as metaphors of mind by the psychological community may be a result of psychologists' differential familiarity with these devices in research practice.

The examples of discovery I gave in this paper are modest instances, compared with the classical literature in the history of science treating the contribution of a Copernicus or a Darwin. But in the narrower context of recent cognitive psychology, however, the theories discussed above count as among the most influential. In this more prosaic context of discovery, the tools-totheories heuristic can account for a group of significant theoretical innovations.

Also, as I have argued, this discovery heuristic can both open and foreclose new avenues of research, depending on the interpretations attached to the statistical tool. My focus was on analytical tools of justification, and I have not dealt with physical tools of experimentation and data processing. Physical tools, once familiar and considered indispensable, also may become the stuff of theories. This holds not only for the hardware (like the software) of the computer, but also for theory innovation beyond recent cognitive psychology. Smith (1986) argued that Edward C. Tolman's use of the maze as an experimental apparatus transformed Tolman's conception of purpose and cognition into spatial characteristics, such as cognitive maps. Similarly, he argued that Clark L. Hull's fascination with conditioning machines has shaped Hull's thinking of behavior as if it were machine design.

The tools-to-theories heuristic connects the contexts of discovery and justification, and shows that the commonly assumed, fixed temporal order between discovery and justification-discovery first, justification second-is not a necessary one. I have discussed cases of discovery where tools for justification came first, and discovery followed. Let me conclude with some reflections on how the present view stands in relation to major themes in scientific discovery.

\section{Data-to-Theories Reconsidered}

Should we continue telling our students that new theories originate from new data, if only because "little is known about how theories come to be created," as J. R. Anderson introduces the reader to his Cognitive Psychology (1980, p. 17)? Holton (1988) noted the tendency among physicists to reconstruct discovery with hindsight as originating from new data, even if this is not the case. His most prominent example is Einstein's special theory of relativity, which was and still is celebrated as an empirical generalization from Michelson's experimental data-by such eminent figures as R. A. Millikan and H. Reichenbach, as well as by textbook writers. As Holton demonstrated with first-hand documents, the role of Michelson's data in the discovery of Einstein's theory was slight, a conclusion shared by Einstein himself.

The strongest claim for an inductive view of discovery came from the Vienna Circle's emphasis on sensory data (reduced to the concept of "pointer readings"). Carnap (1928/1969), Reichenbach (1938), and others focused on what they called the "rational reconstruction" of actual discovery rather than on actual discovery itself, in order to screen out the "merely" irrational and psychological. For instance, Reichenbach reconstructed Einstein's special theory of relativity as being "suggested by closest adherence to experimental facts," a claim that Einstein rejected, as mentioned above (see Holton, 1988, p. 296). It seems fair to say that all attempts to logically reconstruct discovery in science have failed in practice (Blackwell, 1983, p. 111). The strongest theoretical disclaimer concerning the possibility of a logic of discovery came from Popper, Hempel, and other proponents of the hypothetico-deductive account, resulting in the judgment that discovery, not being logical, occurs irrationally. Theories are simply "guesses guided by the 
unscientific" (Popper, 1935/1959, p. 278). But rational induction and irrational guesses are not exhaustive of scientific discovery, and the tools-to-theories heuristic explores the field beyond.

\section{Scientists' Practice Reconsidered}

The tools-to-theories heuristic is about scientists' practice, that is, the analytical and physical tools used in the conduct of empirical research. This practice has a long tradition of neglect. The very philosophers who called themselves logical empiricists had, ironically, no interest in the empirical practice of scientists. Against their reduction of observation to pointer reading, Kuhn (1970) has emphasized the theory-ladenness of observation. Referring to perceptual experiments and Gestalt switches, he says, "scientists see new and different things when looking with familiar instruments in places they have looked before ..." (p. 111). Both the logical empiricists and Kuhn were highly influential on psychology (see Toulmin \& Leary, 1985), but neither view has emphasized the role of tools and experimental conduct. Their role in the development of science has been grossly underestimated until recently (Danziger, 1985, 1987, 1990; Lenoir, 1988).

Through the lens of theory, we are told, we can understand the growth of knowledge. But there is a recent move away from a theory-dominated account of science that pays attention to what really happens in the laboratories. Hacking (1983) argued that experimentation has a life of its own, and that not all observation is theory-laden. Galison (1987) analyzed modern experimental practice, such as in high-energy physics, focusing on the role of the fine-grained web of instruments, beliefs, and practice that determine when a "fact" is considered to be established and when experiments end. Both Hacking and Galison emphasized the role of the familiarity experimenters have with their tools, and the importance and relative autonomy of experimental practice in the quest for knowledge. This is the broader context in which the present tools-totheories heuristic stands: the conjecture that theory is inseparable from instrumental practices.

In conclusion, my argument is that discovery in recent cognitive psychology can be understood beyond mere inductive generalizations or lucky guesses. More than that, I argue that for a considerable group of cognitive theories, neither induction from data nor lucky guesses played an important role. Rather, these innovations in theory can be accounted for by the tools-to-theories heuristic, as can conceptual problems and possibilities in current theories. Scientists' tools are not neutral. In the present case, the mind has been recreated in their image.

\section{References}

Aaronson, D., Grupsmith, E., \& Aaronson, M. (1976). The impact of computers on cognitive psychology. Behavioral Research Methods \& Instrumentation, 8, 129-138.

Anderson, J. R. (1980). Cognitive psychology and its implications. San Francisco: Freeman.

Anderson, J. R., \& Milson, R. (1989). Human memory: An adaptive perspective. Psychological Review, 96, 703 719.

Arbib, M. A. (1993). Allen Newell, unified theories of cognition. Artificial Intelligence, 59, 265-283.

Aspray, W. (1990). John von Neumann and the origins of modern computing. Cambridge, MA: MIT Press.

Baars, B. J. (1986). The cognitive revolution in psychology. New York: Guilford Press.

Babbage, C. (1994). Passages from the life of a philosopher (M. Campbell-Kelley, Ed.). Piscataway, NJ: IEEE Press. (Original work written c. 1812)

Birnbaum, M. H. (1983). Base rates in Bayesian inference: Signal detection analysis of the cab problem. American Journal of Psychology, 96, 85-94.

Blackwell, R. J. (1983). Scientific discovery: The search for new categories. New Ideas in Psychology, 1, 111-115.

Boole, G. (1958). An investigation of the laws of thought. New York: Dover. (Original work published in 1854) 
Brehmer, B., \& Joyce, C. R. B. (Eds.). (1988). Human judgment: The SJT view. Amsterdam: North-Holland. Brown, W., \& Thomson, G. H. (1921). The essentials of mental measurement. Cambridge, UK: Cambridge University Press.

Brunswik, E. (1943). Organismic achievement and environmental probability. Psychological Review, 50, 255-272.

Carnap, R. (1969). The logical structure of the world (R. A. George, Trans.). Berkeley: University of California Press. (Original work published in 1928)

Castellan, N. J. (1981). On-line computers in psychology: The last 10 years, the next 10 years-the challenge and the promise. Behavioral Research Methods \& Instrumentation, 13, 91-96.

Castellan, N. J. (1991). Computers and computing in psychology: Twenty years of progress and still a bright future. Behavior Research Methods, Instruments, \& Computers, 23, 106-108.

Cohen, L. J. (1986). The dialogue of reason. Oxford: Clarendon Press.

Colebrooke, H. (1825). Address on presenting the gold medal of the astronomical society to Charles Babbage. Memoirs of the Astronomical Society, 1, 509-512.

Cronbach, L. J. (1957). The two disciplines of scientific psychology. American Psychologist, 12, 671-684.

Danziger, K. (1985). The methodological imperative in psychology. Philosophy of the Social Sciences, 16, 1-13.

Danziger, K. (1987). Statistical method and the historical development of research practice in American psychology. In L. Krüger, G. Gigerenzer, \& M. S. Morgan (Eds.), The probabilistic revolution: Vol. II. Ideas in the sciences (pp. 35-47). Cambridge, MA: MIT Press.

Danziger, K. (1990). Constructing the subject: Historical origins of psychological research. Cambridge, UK: Cambridge University Press.

Dashiell, J. F. (1939). Some rapprochements in contemporary psychology. Psychological Bulletin, 36, 1-24.

Daston, L. (1988). Classical probability in the enlightenment. Princeton, NJ: Princeton University Press.

Daston, L. (1992). The naturalized female intellect. Science in Context, 5, 209-235.

Daston, L. (1994). Enlightenment calculations. Critical Inquiry, 21, 182-202.

de Finetti, B. (1989). Probabilism. Erkenntnis, 31, 169-223. (Original work published in 1931)

Edgington, E. E. (1974). A new tabulation of statistical procedures used in APA journals. American Psychologist, $29,25-26$.

Fechner, G.T. (1897). Kollektivmasslehre [The measurement of collectivities]. Leipzig: W. Engelmann.

Fisher, R. A. (1955). Statistical methods and scientific induction. Journal of the Royal Statistical Society, B (17), 69-78.

Galison, P. (1987). How experiments end. Chicago: Chicago University Press.

Gardner, H. (1985). The mind's new science. New York: Basic Books.

Gardner, H. (1988). Creative lives and creative works: A synthetic scientific approach. In R. J. Sternberg (Ed.), The nature of creativity (pp. 298-321). Cambridge, UK: Cambridge University Press.

Gavin, E. A. (1972). The causal issue in empirical psychology from hume to the present with emphasis upon the work of Michotte. Journal of the History of the Behavioral Sciences, 8, 302-320.

Gigerenzer, G. (1987a). Probabilistic thinking and the fight against subjectivity. In L. Krüger, G. Gigerenzer, \& M. S. Morgan (Eds.), The probabilistic revolution: Vol. II. Ideas in the sciences (pp. 11-33). Cambridge, MA: MIT Press.

Gigerenzer, G. (1987b). Survival of the fittest probabilist: Brunswik, Thurstone, and the two disciplines of psychology. In L. Krüger, G. Gigerenzer, \& M. S. Morgan (Eds.), The probabilistic revolution: Vol. II. Ideas in the sciences (pp. 49-72). Cambridge, MA: MIT Press.

Gigerenzer, G. (1991). From tools to theories: A heuristic of discovery in cognitive psychology. Psychological Review, 98, 254-267.

Gigerenzer, G. (1992). Discovery in cognitive psychology: New tools inspire new theories. Science in Context, 5, $329-350$.

Gigerenzer, G. (1993). The superego, the ego, and the id in statistical reasoning. In G. Keren \& G. Lewis (Eds.), A handbook for data analysis in the behavioral sciences: Methodological issues (pp. 313-339). Hillsdale, NJ: Erlbaum.

Gigerenzer, G. (1994). Where do new ideas come from? In M. A. Boden (Ed.), Dimensions of creativity (pp. 53 74). Cambridge, MA: MIT Press.

Gigerenzer, G. (2000). Adaptive thinking: Rationality in the real world. New York: Oxford University Press.

Gigerenzer, G. (2001). Ideas in exile: The struggles of an upright man. In K. R. Hammond \& T. R. Stewart (Eds.), The essential Brunswik: Beginnings, explications, applications (pp. 445-452). New York: Oxford University Press.

Gigerenzer, G., \& Goldstein, D. G. (1996). Mind as computer: The birth of a metaphor. Creativity Research Journal, 9, 131-144.

Gigerenzer, G., \& Murray, D. J. (1987). Cognition as intuitive statistics. Hillsdale, NJ: Erlbaum.

Gigerenzer, G., Swijtink, Z., Porter, T., Daston, L., Beatty, J., \& Krüger, L. (1989). The empire of chance: How probability changed science and everyday life. Cambridge, UK: Cambridge University Press. 
Gleick, J. (1992). Genius. The life and science of Richard Feynman. New York: Pantheos.

Good, I. J. (1971). 46656 varieties of Bayesians. The American Statistician, 25, 62-63.

Gooding, D., Pinch, T., \& Schaffer, S. (Eds.). (1989). The uses of experiment: Studies in the natural sciences. Cambridge. UK: Cambridge University Press.

Gruber, H. (1981). Darwin on man, a psychological study of scientific creativity (2nd ed.). Chicago: University of Chicago Press.

Guilford, J. P. (1954). Psychometric methods (2nd ed.). New York: McGraw-Hill.

Hacking, I. (1965). Logic of statistical inference. Cambridge, UK: Cambridge University Press.

Hacking, I. (1975). The emergence of probability. Cambridge, UK: Cambridge University Press.

Hacking, I. (1983). Representing and intervening. Cambridge, UK: Cambridge University Press.

Hammond, K. R., \& Stewart, T. R. (Eds.). (2001). The essential Brunswik: Beginnings, explications, applications. New York: Oxford University Press.

Hanson, N. R. (1958). Patterns of discovery. Cambridge, UK: Cambridge University Press.

Harvard University Center for Cognitive Studies. (1963). Third annual report.

Harvard University Center for Cognitive Studies. (1964). Fourth annual report.

Harvard University Center for Cognitive Studies. (1966). Sixth annual report.

Harvard University Center for Cognitive Studies. (1968). Eighth annual report.

Harvard University Center for Cognitive Studies. (1969). Ninth annual report.

Heims, S. (1975). Encounter of behavioral sciences with new machine-organism analogies in the 1940's. Journal of the History of the Behavioral Sciences, 11, 368-373.

Herbart, J. F. (1816). Lehrbuch zur Psychologie. Hamburg and Leipzig: G. Hartenstein.

Hilgard, E. R. (1955). Discussion of probabilistic functionalism. Psychological Review, 62, 226-228.

Holton, G. (1988). Thematic origins of scientific thought (2nd ed.). Cambridge, MA: Harvard University Press.

Johnson-Laird, P. N. (1983). Mental models. Cambridge, UK: Cambridge University Press.

Kahneman, D., Slovic, P., \& Tversky, A. (Eds.). (1982). Judgment under uncertainty: Heuristics and biases. Cambridge, UK: Cambridge University Press.

Kelley, H. H. (1967). Attribution theory in social psychology. In D. Levine (Ed.), Nebraska Symposium on Motivation (Vol. 15, pp. 192-238). Lincoln: University of Nebraska Press.

Kelley, H. H., \& Michaela, I. L. (1980). Attribution theory and research. Annual Review of Psychology, 31, 457501.

Kendall, M. G. (1942). On the future of statistics. Journal of the Royal Statistical Society, 105, 69-80.

Kita, S. (1993). Language and thought interface: A study of spontaneous gestures and Japanese mimetics. Unpublished doctoral dissertation, University of Chicago.

Kuhn, T. (1970). The structure of scientific revolutions (2nd ed.). Chicago: University of Chicago Press.

Langley, P., Simon, H. A., Bradshaw, G. L., \& Zytkow, J. M. (1987). Scientific discovery. Cambridge, MA: MIT Press.

Leary, D. E. (1987). From act psychology to probabilistic functionalism: The place of Egon Brunswik in the history of psychology. In M. S. Ash \& W. R. Woodward (Eds.), Psychology in twentieth-century thought and society (pp. 115-142). Cambridge, UK: Cambridge University Press.

Leibniz, G. W. von. (1951). The horizon of human doctrine. In P. P. Wiener (Ed.), Selections (pp. 73-77). New York: Scribner's. (Original work published 1690)

Lenoir, T. (1986). Models and instruments in the development of electrophysiology, 1845-1912. Historical Studies in the Physical Sciences, 17, 1-54.

Lenoir, T. (1988). Practice, reason, context: The dialogue between theory and experiment. Science in Context, 2, $3-22$.

Levelt, W. J. M. (1989). Speaking: From intention to articulation. Cambridge, MA: MIT Press.

Levinson, S. (1992). How to think in order to speak Tzeltal. Unpublished manuscript, Max Planck Institute for Psycholinguistics, Nijmegen, The Netherlands (Cognitive Anthropology Group).

Lopes, L. L. (1981). Decision making in the short run. Journal of Experimental Psychology: Human Learning and Memory, 7, 377-385.

Lopes, L. L. (1982). Doing the impossible: A note on induction and the experience of randomness. Journal of Experimental Psychology: Learning, Memory, and Cognition, 8, 626-636.

Lopes, L. L. (1991). The rhetoric of irrationality. Theory and Psychology, 1, 65-82.

Lovie, A. D. (1983). Attention and behaviorism-fact and fiction. British Journal of Psychology, 74, 301-310.

Luce, R. D. (1977). Thurstone's discriminal processes fifty years later. Psychometrika, 42, 461-489.

McArthur, L. A. (1972). The how and what of why: Some determinants and consequents of causal attribution. Journal of Personality and Social Psychology, 22, 171-193.

McCorduck, P. (1979). Machines who think. San Francisco: Freeman.

McCulloch, W. S. (1965). Embodiments of mind. Cambridge, MA: MIT Press. 
Melton, A. W. (1962). Editorial. Journal of Experimental Psychology, 64, 553-557.

Michotte, A. (1963). The perception of causality. London: Methuen. (Original work published 1946)

Miller, G. A., Galanter, E., \& Pribram, K. H. (1960). Plans and the structure of behavior. New York: Holt, Reinhart and Winston.

Mises, R. von. (1957). Probability, statistics, and truth. London: Allen and Unwin.

Murdock, B. B., Jr. (1982). A theory for the storage and retrieval of item and associative information. Psychological Review, 89, 609-626.

Neumann, J. von. (1958). The computer and the brain. New Haven, CT: Yale University Press.

Newell, A., Shaw, J. C., \& Simon, H. A. (1958). Elements of a theory of human problem solving. Psychological Review, 65, 151-166.

Newell, A., \& Simon. H. A. (1972). Human problem solving. Englewood Cliffs, NJ: Prentice-Hall.

Neyman, J. (1937). Outline of a theory of statistical estimation based on the classical theory of probability. Philosophical Transactions of the Royal Society (Series A), 236, 333-380.

Neyman, J., \& Pearson, E. S. (1928). On the use and interpretation of certain test criteria for purposes of statistical inference. Part I. Biometrika 20A, 175-240.

Nickles, T. (1980). Introductory essay: Scientific discovery and the future of philosophy of science. In T. Nickles (Ed.), Scientific discovery, logic, and rationality (pp. 1-59). Dordrecht: Reidel.

Piaget, J. (1930). The child's conception of causality. London: Kegan Paul.

Popper, K. (1959). The logic of scientific discovery. New York: Basic Books. (Original work published in 1935)

Reichenbach, H. (1938). Experience and prediction. Chicago: University of Chicago Press.

Rucci, A. J., \& Tweney, R. D. (1980). Analysis of variance and the "Second Discipline" of scientific psychology: A historical account. Psychological Bulletin, 87, 166-184.

Schaffer, S. (1992). Disappearing acts: On Gigerenzer's “Where Do New Ideas Come From?” Unpublished manuscript.

Schaffer, S. (1994). Babbage's intelligence: Calculating engines and the factory system. Critical Inquiry, 21, 203 227.

Searle, J. (1984). Minds, brains and science. Cambridge, MA: Harvard University Press.

Simon, H. A. (1969). The sciences of the artificial. Cambridge, MA: MIT Press.

Simon, H. A. (1979). Information processing models of cognition. Annual Review of Psychology, 30, 363-396.

Simon, H. A. (1991). Models of my life. New York: Basic Books.

Simon, H. A. (1992). What is an "explanation" of behavior? Psychological Science, 3, 150-161.

Simon, H. A. (1994). Personal communication.

Simon, H. A., \& Newell, A. (1986). Information processing language V on the IBM 650. Annals of the History of Computing, 8, 47-49.

Smith, L. D. (1986). Behaviorism and logical positivism. Stanford, CA: Stanford University Press.

Sterling, T. D. (1959). Publication decisions and their possible effects on inferences drawn from tests of significance or vice versa. Journal of the American Statistical Association, 54, 30-34.

Swets, J. A., Tanner, W. D., \& Birdsall, T. G. (1964). Decision processes in perception. In J. A. Swets (Ed.), Signal detection and recognition in human observers (pp. 3-57). New York: Wiley.

Swijtink, Z. G. (1987). The objectification of observation: Measurement and statistical methods in the nineteenth century. In L. Krüger, L. J. Daston, \& M. Heidelberger (Eds.), The probabilistic revolution: Vol. I. Ideas in history (pp. 261-285). Cambridge, MA: MIT Press.

Tanner, W. P., Jr. (1965). Statistical decision processes in detection and recognition (Technical Report). Ann Arbor: University of Michigan, Sensory Intelligence Laboratory, Department of Psychology.

Tanner, W. P., Jr., \& Swets, J. A. (1954). A decision-making theory of visual detection. Psychological Review, 61, 401-409.

Teigen, K. H. (1983). Studies in subjective probability IV: Probabilities, confidence, and luck. Scandinavian Journal of Psychology, 24, 175-191.

Thorndike, R. L. (1954). The psychological value systems of psychologists. American Psychologist, 9, 787-789.

Thurstone, L. L. (1927). A law of comparative judgement. Psychological Review, 34, 273-286.

Titchener, E. B. (1896). An outline of psychology. New York: Macmillan.

Toulmin, S., \& Leary, D. E. (1985). The cult of empiricism in psychology, and beyond. In S. Koch (Ed.), A century of psychology as science (pp. 594-617). New York: McGraw-Hill.

Turing, A. M. (1950). Computing machinery and intelligence. Mind, 59, 433-460.

Turing, A. M. (1969). Intelligent machinery. In B. Meltzer \& D. Michie (Eds.), Machine intelligence, 5. Edinburgh, UK: Edinburgh University Press.

Tversky, A., \& Kahneman, D. (1974). Judgment under uncertainty: Heuristics and biases. Science, 185, 11241131. 
Tversky, A., \& Kahneman, D. (1980). Causal schemata in judgments under uncertainty. In M. Fishbein (Ed.), Progress in social psychology (Vol. I, pp. 49-72). Hillsdale, NJ: Erlbaum.

Tversky, A., \& Kahneman, D. (1982). Judgments of and by representativeness. In D. Kahneman, P. Slovic, \& A. Tversky (Eds.), Judgment under uncertainty: Heuristics and biases (pp. 84-98). Cambridge, UK: Cambridge University Press.

Tversky, A., \& Kahneman, D. (1983). Extensional versus intuitive reasoning: The conjunction fallacy in probability judgment. Psychological Review, 90, 293-315.

Tweney, R. D., Dotherty, M. E., \& Mynatt, C. R. (Eds.). (1981). On scientific thinking. New York: Columbia University Press.

Whitehead, A. N., \& Russell, B. (1935). Principia mathematica (2nd ed., Vol. 1). Cambridge, UK: Cambridge University Press.

Wickelgreen, W. A., \& Norman, D. A. (1966). Strength models and serial position in short-term recognition memory. Journal of Mathematical Psychology, 3, 316-347. 